\title{
Influence of Back Support Conditions on the Apparent Mass of Seated Occupants under Horizontal Vibration
}

\author{
Santosh C. MANDAPURAM ${ }^{1}$, Subhash RAKHEJA ${ }^{1 *}$, Shiping MA ${ }^{2}$, \\ Richard G. DEMONT ${ }^{2}$ and Paul-Émile BOILEAU ${ }^{3}$
}

${ }^{1}$ CONCAVE Research Center, Concordia University, 1455 de Maisonneuve West, Montreal, QC, H3G 1M8 Canada
${ }^{2}$ Department of Exercise Sciences, Concordia University, 1455 de Maisonneuve West, Montreal, QC, H3G 1M8 Canada
${ }^{3}$ Institut de recherche Robert-Sauvé en santé et en sécurité du travail, 505 de Maisonneuve West, Montréal, QC,
H3A 3C2 Canada

Received February 25, 2005 and accepted March 30, 2005

\begin{abstract}
The response characteristics of seated human subjects exposed to fore-aft ( $x$-axis) and lateral ( $y$-axis) vibration are investigated through measurements of dynamic interactions between the seated body and the seat pan, and the upper body and the seat backrest. The experiments involved: (i) three different back support conditions (no back support, and upper body supported against a vertical and an inclined backrest); (ii) three different seat pan heights $(425,390$ and 350 $\mathrm{mm})$; and three different magnitudes $\left(0.25,0.5\right.$ and $1.0 \mathrm{~m} / \mathrm{s}^{2} \mathrm{rms}$ acceleration) of band limited random excitations in the $0.5-10 \mathrm{~Hz}$ frequency range, applied independently along the fore-aft and lateral directions in an uncoupled manner. The body force responses, measured at the seat pan and the backrest along the direction of motion, are applied to characterize the total body apparent mass (APMS) reflected on the seat pan, and those of the upper body reflected on the backrest. Unlike the widely reported responses of seated occupants under vertical vibration, the responses to horizontal vibration show strong effect of excitation magnitude. The large displacements at lower frequencies cause considerable rotations of the upper body, and the knees and ankles, particularly when seated without a back support, which encouraged the occupants to continually shift larger portion of the body weight towards their feet. This together with the strong dependence on the excitation magnitude resulted in considerable inter-subject variability of the data. The addition of a back support causes stiffening of the body to limit the low frequency rocking motion of the upper body under $\boldsymbol{x}$-axis motion, while considerable dynamic interactions with the backrest occur. The mean apparent mass (APMS) responses measured at the seat pan and the backrest suggest strong contributions due to the back support condition, and the direction and magnitude of horizontal vibration, while the role of seat height is important only in the vicinity of the resonant frequencies. In the absence of a back support, the seat pan responses predominate at a lower frequency (near $0.7 \mathrm{~Hz}$ ) under both directions of motion, while two secondary peaks in the magnitude also occur at relatively higher frequencies. The addition of back support causes the seat pan response to converge mostly to a single primary peak, resulting in a single-degree-of-freedom like behavior, with peak occurring in the $2.7-5.4 \mathrm{~Hz}$ range under $x$-axis, and $0.9-2.1 \mathrm{~Hz}$ range under $y$-axis motions, depending upon the excitation magnitude and the back support condition. This can be attributed to the stiffening of the body in the presence of the constraints imposed by the backrest. A relaxed posture with an inclined backrest, however, causes a softening effect, when compared to an erect posture with a vertical backrest. The backrest, however, serves as another source of vibration to the seated occupant, which tends to cause considerably higher magnitude responses. The considerable magnitudes of the apparent mass
\end{abstract}

*To whom correspondence should be addressed. 
response measured at the seat back under fore-aft motions suggest strong interactions with the backrest. Such interactions along the side-to-side motions, however, are relatively small. The results suggest that the biodynamic characterization of seated occupants exposed to horizontal vibration requires appropriate considerations of the interactions with the backrest.

Key words: Apparent mass response to horizontal vibration, Biodynamic response of seated occupants, Sitting postures, Back support condition, Seat height, Body-seat dynamic interactions, Body-backrest dynamic interactions

\section{Introduction}

Seated human occupants' responses to whole-body vibration have been widely investigated in terms of forcemotion relationships at the body-seat pan driving-point. The majority of these studies focus on response analyses of seated body exposed to vertical vibration ${ }^{1-5)}$, since the magnitudes of vertical vibration encountered in road- and off-road vehicles are generally believed to be higher than those along the other axis, and cause more detrimental effects in view of operator health and safety. While the nature of horizontal vibration transmitted along the horizontal-axes is also known to be quite severe, particularly for many off-road vehicles, only a few studies have investigated the force-motion relationships under vibration along the longitudinal ( $x$-axis) and lateral ( $y$-axis) directions ${ }^{6-9)}$. The relatively low flexibility of tires of off-road vehicles coupled with high location of the operator, and presence of localized slopes and crossslopes in the terrain, contribute to considerable motions at the operators' location along the $x$ - and $y$-axes.

Many studies have reported appreciable magnitudes of horizontal motions transmitted to operators of the off-road tractors. For off-road tractors with implements or when ploughing, harrowing or drilling, the magnitudes of frequency-weighted longitudinal and lateral vibration could be either comparable to or exceed that of the vertical vibration $^{10-12)}$. The relative magnitudes of horizontal vibration, however, would depend upon the type of vehicle and the task performed. On the basis of measurements performed on tractors, Kumar et al. ${ }^{10)}$ concluded that the ratio of lateral and longitudinal vibration to the vertical vibration lie in the 0.48 to 0.6 range. Marsili et al. ${ }^{11)}$ concluded that the magnitude of lateral vibration could be higher than the vertical vibration during transport operation. Similar conclusions have also been drawn for many construction and industrial vehicles, namely, excavators, off-road forklift trucks, port cranes ${ }^{12-14)}$. The longitudinal and lateral vibrations of wheeled off-road vehicles generally predominate in the $2-4.5 \mathrm{~Hz}$ range, and around $1 \mathrm{~Hz}$, respectively. A few studies have also suggested various lateral and longitudinal mode resonances of the seated body in the 0.5 to $12 \mathrm{~Hz}$ frequency range, and that the exposure to horizontal vibration in the $0.1-0.75 \mathrm{~Hz}$ range could trigger motion sickness in roughly half the time that would be needed to cause the same under vertical vibration ${ }^{15-17)}$.

The reported studies on the biodynamic responses of human occupants exposed to vertical vibration have provided considerable insights into the resonant behavior of the biological system, and the role of posture and seat design factors in view of potentially injurious effects of the exposure $^{1-4)}$. Owing to the comparable magnitudes of lowfrequency horizontal vibration encountered in off-road vehicle driving, similar additional studies under exposure to such vibration would be desirable to enhance knowledge on the behavior of the seated body under longitudinal and lateral motions, and to identify some of the critical seating and environment factors related to detrimental effects of the exposure. The force-motion relationships at the drivingpoint(s) of a seated body are known to be complex functions of many factors related to the occupant, seat design, assumed posture and nature of the vibration exposure. The reported studies under vertical vibration have clearly established the strong effects of body mass and build, frequency of vibration, seat height, back support condition, etc. ${ }^{1,45)}$. Thus far, only limited efforts have been made to study the role of some of these factors on the biodynamic responses under exposure to horizontal vibration ${ }^{6,7)}$, although a number of studies have focused on the comfort and perception of horizontal vibration $^{6-9)}$, and motion sickness effects ${ }^{15-17)}$.

Holmlund and Lundstrom ${ }^{8}$ investigated the driving-point mechanical impedance at the seat base of male and female subjects seated without a back support and exposed to sinusoidal vibration along the orthogonal $x$ - and $y$-axes in the $1.13-80 \mathrm{~Hz}$ frequency range. The measurements performed under six different magnitudes of harmonic vibration, ranging from 0.25 to $1.4 \mathrm{~m} / \mathrm{s}^{2} \mathrm{rms}$ acceleration, revealed a peak magnitude in the $3-5 \mathrm{~Hz}$ range under $x$ axis motion, and two distinct peaks in the $2-5 \mathrm{~Hz}$ and $5-7$ 
$\mathrm{Hz}$ ranges under $y$-axis motion. The peak magnitude of the second peak decreased when the upper body posture was changed from erect to relaxed. The study showed higher impedance magnitude for the male subjects, when compared to those of the female subjects. Mansfield and Lundtrom ${ }^{9)}$ measured the apparent mass (APMS) of the same number of male and female subjects seated without a back support under non-orthogonal horizontal random vibration in the $1.5-20 \mathrm{~Hz}$ frequency range of different magnitudes $(0.25$, 0.5 and $1.0 \mathrm{~m} / \mathrm{s}^{2} \mathrm{rms}$ acceleration). The results revealed two distinct peaks in the $x$ - and $y$-axes magnitudes, near 3 and $5 \mathrm{~Hz}$, and in the 2 to 5 and 5 to $7 \mathrm{~Hz}$ frequency ranges, respectively. The responses to non-orthogonal horizontal vibration were measured along different axis with respect to the mid-sagittal plane, while the frequency of the identified primary peak reduced as the direction of vibration changed from $x$ - to $y$-axis. An increase in the vibration magnitude resulted in slightly lower frequency of the primary peak, which was attributed to the softening of the body that has also been reported in many studies on vertical biodynamics.

The above studies have employed harmonic and random vibration at frequencies above $1 \mathrm{~Hz}$, and thus could not identify the peak magnitude response at frequencies below $1 \mathrm{~Hz}$ that has been observed for occupants seated without a back support and exposed to horizontal vibration in the 0.25 $20 \mathrm{~Hz}$ of different magnitudes $\left(0.5,1.0\right.$ and $2.0 \mathrm{~m} / \mathrm{s}^{2} \mathrm{rms}$ acceleration $)^{7}$, which is most likely attributed to the pitch motion of the upper body. The secondary peak in the 5-7 $\mathrm{Hz}$ range in both the $x$ and $y$ - axes, however, could not be observed in this study due to the higher magnitudes of acceleration considered, which is most likely attributed to the motion of the hands and the legs ${ }^{9}$. Under exposure to horizontal vibration, specifically along the longitudinal axis, a seat backrest serves as an important constraint for the upper body movement, and would thereby affect the biodynamic response considerably. Fairley and Griffin ${ }^{7)}$ reported the apparent mass responses of occupants seated with and without a back support and exposed to horizontal vibration. The data attained for the back-supported posture revealed a single primary peak in the magnitudes near $3.5 \mathrm{~Hz}$ in the $x$-axis and near $1.5 \mathrm{~Hz}$ in the $y$-axis responses. Nawayseh and Griffin $^{6}$ studied the occupants' interactions with the backrest under fore-aft motion through measurements of contact forces. The study revealed considerably higher magnitudes of the force along $x$-axis, while those along the $y$-and $z$ axes were very small. The study further showed significant effect of the feet support on the measured APMS response.

The magnitudes of dynamic interactions between the upper body and the seat backrest would depend upon the degree of support and the inclination of the backrest. The vehicle seats are designed to provide enhanced support for the occupant back through an inclined backrest, which may yield different magnitudes of dynamic forces at the body-backrest interface and thus need to be examined. Furthermore, the support against a backrest may cause increased transmission of vibration to the seated body. The total characterization of the seated body biodynamic response to horizontal vibration may thus require consideration of two drivingpoints, the seat pan and the backrest.

In this study, the force-motion responses of seated occupants exposed to constant acceleration spectrum random horizontal vibration in the 0.5 to $10 \mathrm{~Hz}$ frequency range are measured at the seat pan and the backrest. The data are used to characterize the dynamic interactions of the body with the seat pan and the backrest in terms of apparent masses under longitudinal and lateral vibration applied independently. The dynamic interactions between the seat and the body are measured under different magnitudes of excitations and postures realized by varying the seat height, backrest inclination and the back support condition.

\section{Methods}

The experiments were conducted using a rigid seat with adjustable backrest and height. The seat consisted of a 500 $\times 400 \mathrm{~mm}$ flat seat pan and a $470 \mathrm{~mm}$ high backrest installed on a truss structure. The seat was installed on a horizontal vibration simulator through two three-axis force plates (Kistler 9257AB) capable of measuring forces at the seat base along the three translational axes. A summing junction was used to sum the force signals from the two force plates along the respective axes, to compute the resultant dynamic force due to the rigid seat and the occupant at the seat pan interface, as illustrated in Fig. 1 for the longitudinal direction of motion. An additional three-axis force plate was also installed between the backrest plate and the seat back truss structure to capture the dynamic forces arising at the occupant's upper body and the backrest interface. Under $x$ axis motion, the force acting along an axis normal to the backrest alone, however, was acquired, since the forces along the lateral and vertical directions of the backrest were expected to be small in magnitude ${ }^{6}$. Under lateral excitations, the measurement of backrest force was limited to $y$-axis alone. Two single-axis accelerometers were further installed on the seat back and the platform, oriented along the axis of motion, to capture the acceleration excitations at the two interface locations. The seat was designed such that it could be easily oriented along the lateral or longitudinal axis of 

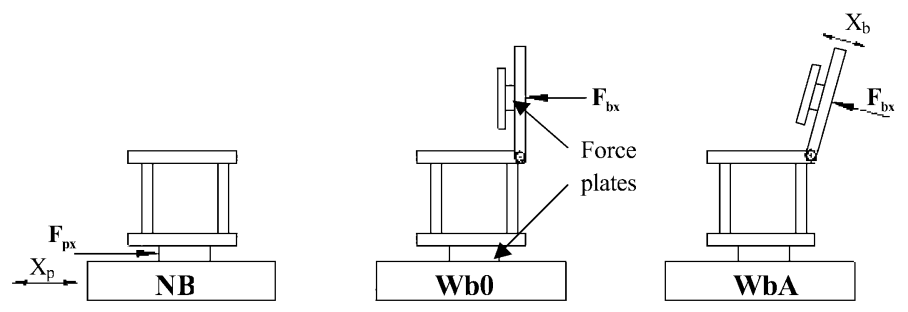

Fig. 1. Schematic illustrations of the three different sitting postures used in the study.

Table 1. Test matrix

\begin{tabular}{|c|c|c|c|}
\hline Posture & $\begin{array}{c}\text { No-back } \\
\text { support, NB }\end{array}$ & $\begin{array}{l}\text { Vertical back } \\
\text { support, Wb0 }\end{array}$ & $\begin{array}{l}\text { Inclined back } \\
\text { support, WbA }\end{array}$ \\
\hline Excitation Magnitude (rms) & $0.25 \mathrm{~m} / \mathrm{s}^{2}$ & $0.5 \mathrm{~m} / \mathrm{s}^{2}$ & $1.0 \mathrm{~m} / \mathrm{s}^{2}$ \\
\hline Seat height & $\mathrm{H}_{1}(425 \mathrm{~mm})$ & $\mathrm{H}_{2}(390 \mathrm{~mm})$ & $\mathrm{H}_{3}(350 \mathrm{~mm})$ \\
\hline Direction of motion & Fore and aft & Lateral & \\
\hline
\end{tabular}

motion of the vibration platform, which consisted of a magnesium slip table sliding on an oil film over a granite slab. The slip table was driven by a $48 \mathrm{~cm}$ stroke servocontrolled hydraulic actuator.

The experiments were performed under excitations along the longitudinal $(x)$ and lateral $(y)$ axes, applied independently in an uncoupled manner. A total of 8 healthy adult male volunteers, aged between $21-51 \mathrm{yr}$, took part in the experiment. The subjects had no prior known history of musculo-skeletal system disorders. The subjects' mass ranged from $59.4 \mathrm{~kg}$ to $92 \mathrm{~kg}$, with mean mass of $71.2 \mathrm{~kg}$ and standard deviation of the mean of $10.6 \mathrm{~kg}$. The standing height of the subjects varied from $1.7 \mathrm{~m}$ to $1.78 \mathrm{~m}$ (mean = $1.73 \mathrm{~m}$ and standard deviation $=0.025 \mathrm{~m}$ ). Prior to the test, each subject was informed about the purpose of the study, experimental set up and usage of the hand-held emergency stop. Each subject was given written information about the experiment and was requested to sign a consent form that was previously approved by a Human Research Ethics Committee.

The measurements were performed for each subject assuming three different sitting postures, three different seat heights (referred to as $\mathrm{H}_{1}, \mathrm{H}_{2}$ and $\mathrm{H}_{3}$ ), and three different levels of vibration along the lateral and longitudinal directions applied independently. The variations in sitting postures were realized by different back support conditions: (i) sitting erect with no back support, NB; (ii) Sitting erect with upper body supported against a vertical backrest, $\mathrm{Wb0}$; and (iii) seated relaxed with upper body supported against backrest inclined at an angle of $12.5^{\circ}$ with respect to the vertical axis
WbA (Fig. 1), as summarized in Table 1. The subjects were seated with their feet supported on the moving platform for each posture. The biodynamic response characteristics of the participants were measured under different levels of constant acceleration spectral density random excitations in the $0.5-10 \mathrm{~Hz}$ frequency range with overall $\mathrm{rms}$ accelerations of $0.25,0.5$ and $1.0 \mathrm{~m} / \mathrm{s}^{2}$, along both the directions. Each subject was asked to put on a cotton lab coat to ensure uniform friction between the back and the backrest, particularly under lateral excitation.

The subjects were advised to sit upright with hands in the lap for the duration of each test with no-back posture and lean against the backrest for tests involving backsupported postures. Each test was performed two times and the data were examined for the repeatability. The resulting test matrix thus included a total of 54 trials for each axis of vibration. The duration of each measurement lasted $128 \mathrm{~s}$, while the subject's posture during a trial was visually checked by the experimenter to ensure consistency.

The seat was initially installed along the longitudinal direction of motion. The force and acceleration signals measured at the seat base and the backrest were acquired using the PulseLabShop ${ }^{\mathrm{TM}}$ data acquisition and analysis system. The measurements were initially performed on the seat alone under selected excitations. The measured data were analyzed to derive the apparent masses of the total seat and the backrest using a bandwidth of $50 \mathrm{~Hz}$ with frequency resolution of $0.0625 \mathrm{~Hz}$. The apparent masses of the total seat and the backrest were derived from the acceleration due to excitation, and the total force measured 
at the seat base and the backrest, respectively. Under longitudinal excitations, these were computed from:

$$
\begin{aligned}
& M_{p x 0}(j \omega)=S_{F_{p x} \ddot{x}} / S_{\ddot{x}} \\
& M_{b x 0}(j \omega)=S_{F_{b x} \ddot{x}_{b}} / S_{\ddot{x}_{b}}
\end{aligned}
$$

Where $M_{p x 0}$ is the complex apparent mass of the total seat corresponding to excitation frequency $\omega$, referred to as seat pan APMS. $S_{F_{p x} x}$ is the cross-spectral density of the total force measured at the seat base along the $x$-axis $\left(F_{p x}\right)$ and the acceleration due to excitation $\ddot{x}$, and $S_{\ddot{x}}$ is acceleration auto spectral density. $M_{b x 0}$ is the complex apparent mass measured of the backrest, referred to as backrest APMS, $S_{F_{b x} x}$ is the cross-spectral density of the force measured at the seat backrest along an axis normal to the backrest $\left(F_{b x}\right)$, as illustrated in Fig. 1, and the acceleration due to excitation along the same direction $\ddot{x}_{b}$, and $S_{\ddot{x}_{b}}$ is acceleration auto spectral density.

The measurements were performed with vertical and inclined backrest. Both the measurements revealed identical constant magnitude of the backrest APMS in the frequency range of interest with nearly zero phase response. It should be noted that $\ddot{x}_{b}=\ddot{x}$ for a vertical backrest, and $\ddot{x}_{b}=\ddot{x} \cos (\alpha)$, where $\alpha$ is the backrest inclination. Since the force measured at an inclined backrest is related to that measured on a vertical backrest by $\cos (\alpha)$, both the measurements yield identical magnitude of the backrest APMS. The seat pan APMS also revealed constant magnitude in the $0.5-10 \mathrm{~Hz}$ frequency range with negligible phase. Under lateral excitations, the total forces acquired at the seat base and the backrest of the seat alone were applied to compute the APMS of the seat and the backrest, respectively, in a similar manner. The measurements revealed constant magnitudes of the APMS in the concerned frequency range $(0.5-10 \mathrm{~Hz})$.

Measurements were performed with the subjects and the total forces measured at the seat pan and the backrest was used to compute the APMS responses of the coupled seatoccupant system using equation (1) for the respective axis of vibration. The measurements at the seat base revealed high coherency of the force and acceleration signals under both axes of motion, greater than 0.97 in the $0.5-10 \mathrm{~Hz}$ frequency range, except for those acquired with the vertical back posture showed greater than 0.95 at frequencies above $5 \mathrm{~Hz}$. The measurements at the backrest along $x$ and $y$-axes also revealed coherence values greater than 0.95 under lower magnitude $\left(0.25 \mathrm{~m} / \mathrm{s}^{2}\right)$ of vibration. The measurements at the backrest under higher magnitude of vibration $\left(1 \mathrm{~m} / \mathrm{s}^{2}\right)$ revealed coherence values greater than 0.9 in the frequency $0.5-4.5 \mathrm{~Hz}$ for both axes of motion. The coherency of the $y$-axis measurements increased with frequency in the higher frequency range but decreased for the $x$-axis measurements with the vertical backrest ( $\mathrm{Wb} 0)$. This was attributed to the rocking motion at the subject's back and intermittent loss of contact with the vertical backrest. The measurements with the inclined backrest, ho wever, revealed good coherency of the force and acceleration signals measured at the backrest under both axes of motion in the entire frequency range. The coherence values generally improved with the decrease in seat height showing increased stability of the posture. The APMS values for the seat pan and the backrest alone were applied to perform the inertial corrections to compute the APMS responses of the seated human occupants under exposure to lateral and longitudinal vibration.

\section{Results and Discussions}

The apparent mass responses measured at the seat pan and the backrest of an individual in two trials were averaged to derive the mean responses, as different trials revealed high degree of consistency. The apparent mass responses of the 8 subjects, however, showed considerable variability in the seat pan as well as the backrest magnitudes but similar trends for all the test conditions considered, particularly the concentration of magnitude peaks around the same frequencies for most of the subjects. The NB posture generally caused a sensation of instability among the subjects and encouraged the subjects to shift more weight to and from their feet, specifically when the displacement was perceived to be high. The higher values coefficients of variation $(\mathrm{CoV})$ of the mean were observed in the vicinity of the frequencies corresponding to peak APMS magnitudes. The CoV of the data acquired under NB postures increased with the magnitude of excitation, while such a trend was not evident from the data acquired for the back supported postures. Peak values of the $\mathrm{CoV}$ of the data acquired at the seat base ranged from $40 \%$ to $54 \%$, depending upon the posture and the magnitude of excitation, while the effect of seat height was relatively small. The orders of these values are comparable to those reported for the seat pan measured biodynamic responses under horizontal vibration ${ }^{9}$. The measurements at the backrest revealed considerably higher variability in the magnitude response, where the peak $\mathrm{CoV}$ approached as high as $90 \%$ in the $1-2 \mathrm{~Hz}$ range. This is believed to be caused by intermittent loss of contact between the upper body and the backrest under fore-aft excitation, sliding against the backrest under side-to-side motion, and subjects' tendency to continually shift more weight towards their feet. 


\section{Normalization of the measured APMS magnitude response}

A number of studies on vertical biodynamic responses of seated individuals and a few on horizontal vibration biodynamics have mostly attributed the dispersion in the measured data to variations in the body mass. The data are thus frequently normalized with a measure of the body mass to reduce the variability and to study the role of other contributing factors ${ }^{1,2,4}$. Owing to the negligible contribution of the legs, the vertical APMS responses are normalized with respect to the static seated mass, ranging from $70-74 \%$ of the total body mass. This further compares well with the APMS magnitude response near $0.5 \mathrm{~Hz}^{1}$. Under horizontal vibration, the APMS magnitudes at such low frequencies are observed to be higher than the static seated mass, suggesting contribution due to a relatively larger portion of the seated body. This may be partly attributed to the presence of a low frequency resonance, particularly with NB posture, and possible influence of the legs. The normalization of the measured data thus requires identification of the representative portions of the body mass reflected at the seat pan and the backrest, while undergoing horizontal motions.

Holmlund and Lundström ${ }^{8)}$ normalized the measured impedance response under horizontal vibration on the basis of the body mass supported by the seat pan. In the present study, the subjects tended to continually shift weight to and from their legs in order to realize a more stable sitting posture. The knee joints rotations about the $y$-axis, and ankles rotations about the $x$ axis were observed under $x$ - and $y$-axis motions, respectively. Mansfield and Lundstrom ${ }^{9}$ speculated that the role of seated occupants legs in the horizontal APMS response may vary with the direction of vibration, and thus normalized the measured APMS response using the total body mass. The effective mass reflected at the seat pan may be considered as the sum of those of the upper body and the thighs, while upper body mass alone would constitute the mass reflected at the backrest. The anthropometric data reported for the North American male population suggest that the upper body and the thighs account for nearly $67.8 \%$ and $20 \%$ of the total body mass, respectively ${ }^{18)}$. The normalization factors for the seat pan and backrest APMS magnitudes are thus taken as $87.8 \%$ and $67.8 \%$, respectively, of the total body mass.

The applications of these normalizing factors resulted in near unity values of the normalized seat pan and backrest APMS magnitudes at low frequencies around $0.5 \mathrm{~Hz}$, with the exception of the $y$-axis backrest APMS, which tends to be considerably lower. This exception is attributed to relatively low level interactions of the upper body with the backrest along the $y$-axis. Figure 2 illustrates comparisons of the magnitude data obtained for individual subjects exposed to $1 \mathrm{~m} / \mathrm{s}^{2} x$ - and $y$-axis vibration and seated with WbA (seat pan and backrest) and NB (seat pan) postures (seat height- $\mathrm{H}_{1}$ ). The normalized magnitude responses for the NB postures clearly show the presence of resonance at frequencies below $1 \mathrm{~Hz}$, and relatively smaller dispersion among the data when compared to the true measured data (not presented). The peak values of $\mathrm{CoV}$ of the mean normalized magnitudes were generally $10 \%$ lower than those observed from the true magnitude data. The figure also shows comparisons of the data attained under same magnitude of lateral excitation, where the dispersion among the data is generally higher. The results also show that the normalized magnitude response at the backrest is well below 1.0 under lateral excitations.

The results show that the peak magnitude responses of the subjects occur within narrow frequency ranges, and are strongly dependent upon the sitting posture and the direction of excitation. The mean normalized magnitude and phase data are evaluated to study the important trends related to the effect of sitting posture, seat height and magnitude of vibration on the seat pan and backrest responses. Owing to the relatively high values of $\mathrm{CoV}$, specifically in the vicinity of the resonant frequencies, the mean data are considered to provide trend information on the effects of various factors. Single and two-factor ANOVA (analysis of variance) are also performed to identify the most significant factors affecting the seat pan and backrest APMS responses. Tables 2 and 3 summarize the $p$-values attained for the $x$ - and $y$ axis seat pan responses, respectively, at different discrete frequencies, considering the three levels each of the excitation magnitude and seat height, and their interactions, for each sitting posture. The significant differences between the seat pan APMS magnitudes obtained for the two back-supported postures ( $\mathrm{Wb} 0$ vs $\mathrm{WbA}$ ) and all three postures are summarized in Table 4 , for both axes of vibration.

\section{Effect of vibration magnitude}

The effect of vibration magnitude on the APMS responses of seated occupants exposed to vertical vibration is known to be relatively small ${ }^{1-5)}$. The responses to horizontal vibration, measured at the seat pan, however, have shown strong effects of the vibration magnitude ${ }^{6-9)}$, which are most likely attributed to many factors, such as, the nonlinear behavior of the seated body, excessive upper body movements under higher excitations, shifting tendencies of the occupants to realize more stable posture, and contributions due to legs. Figure 3 illustrates comparisons of the mean seat pan APMS 

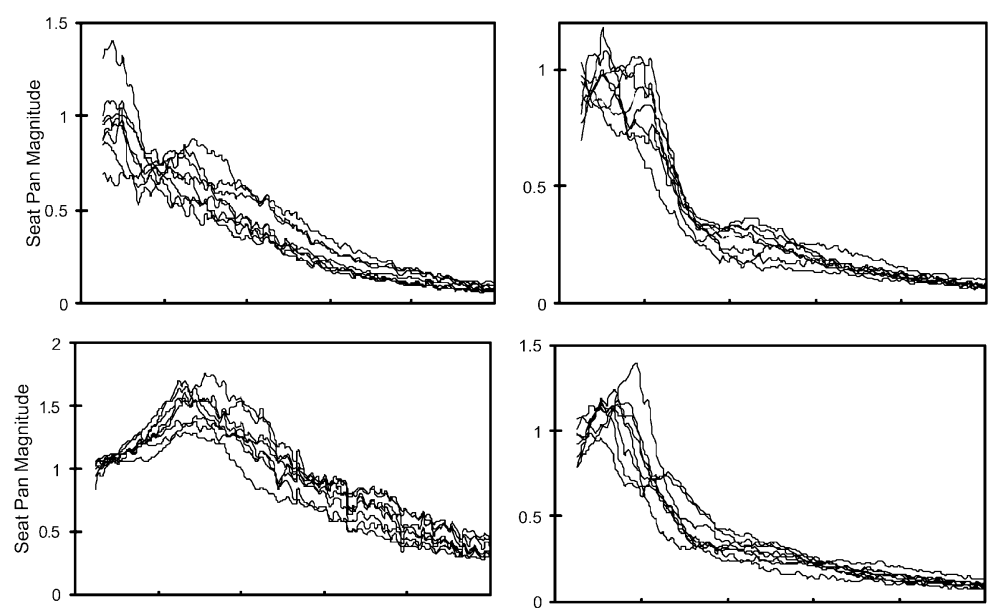

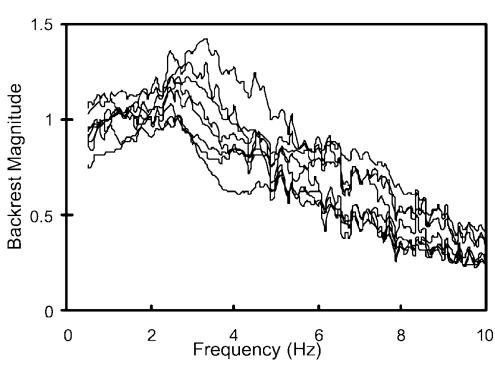

(a) $X$-axis

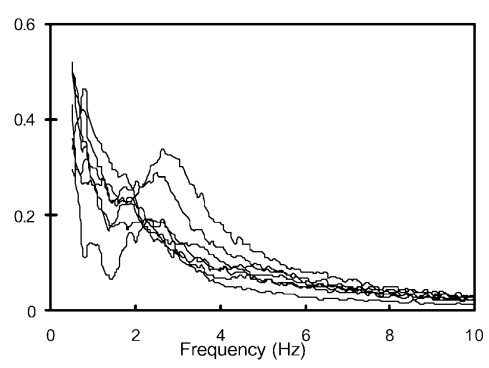

(b) $Y$-axis

Fig. 2. Comparison of normalized APMS magnitude responses measured at the seat pan and backrest of eight subjects seated with NB and WbA postures, and exposed to $1 \mathrm{~m} / \mathrm{s}^{2}$ rms acceleration (seat height $\mathrm{H}_{1}$ ).

Table 2. $p$-values attained from single and two-factor ANOVA performed on the seat pan APMS magnitude under fore-aft vibration

\begin{tabular}{|c|c|c|c|c|c|c|c|c|c|}
\hline \multirow{2}{*}{$\begin{array}{l}\text { Factor } \\
\text { Frequency }(\mathrm{Hz})\end{array}$} & \multicolumn{3}{|c|}{ Excitation $\left(.25, .5,1.0 \mathrm{~m} / \mathrm{s}^{2}\right)$} & \multicolumn{3}{|c|}{ Height $\left(\mathrm{H}_{1}, \mathrm{H}_{2}, \mathrm{H}_{3}\right)$} & \multicolumn{3}{|c|}{ Excitation*Height } \\
\hline & NB & Wb0 & $\mathrm{WbA}$ & NB & Wb0 & $\mathrm{WbA}$ & NB & Wb0 & $\mathrm{WbA}$ \\
\hline 0.75 & 0.000 & 0.049 & 0.970 & 0.041 & 0.009 & 0.088 & 0.63 & 0.729 & 0.11 \\
\hline 1.0 & 0.000 & 0.013 & 0.506 & 0.000 & 0.118 & 0.018 & 0.489 & 0.055 & 0.299 \\
\hline 1.5 & 0.002 & 0.000 & 0.000 & 0.000 & 0.763 & 0.115 & 0.012 & 0.536 & 0.008 \\
\hline 2 & 0.949 & 0.000 & 0.000 & 0.220 & 0.304 & 0.005 & 0.15 & 0.435 & 0.031 \\
\hline 2.75 & 0.000 & 0.001 & 0.000 & 0.005 & 0.043 & 0.004 & 0.063 & 0.141 & 0.209 \\
\hline 4 & 0.000 & 0.383 & 0.000 & 0.004 & 0.001 & 0.478 & 0.03 & 0.013 & 0.015 \\
\hline 4.5 & 0.000 & 0.021 & 0.000 & 0.002 & 0.003 & 0.725 & 0.02 & 0.001 & 0.403 \\
\hline 5 & 0.000 & 0.000 & 0.000 & 0.083 & 0.051 & 0.958 & 0.063 & 0.001 & 0.913 \\
\hline 6 & 0.000 & 0.000 & 0.000 & 0.337 & 0.378 & 0.623 & 0.325 & 0.008 & 0.194 \\
\hline 8 & 0.000 & 0.000 & 0.000 & 0.110 & 0.007 & 0.454 & 0.129 & 0.233 & 0.921 \\
\hline
\end{tabular}

responses (normalized magnitude and phase) attained under different magnitudes of $x$ - and $y$-axes of excitations, and NB posture. Figures 4 and 5 illustrate the effects of excitation magnitude on the $x$ - and $y$-axis seat pan and backrest APMS responses for the $\mathrm{Wb} 0$ and $\mathrm{WbA}$ postures, respectively. The results clearly show strong and nonlinear effects of vibration magnitude on both the seat pan and backrest responses, irrespective of the direction of excitation. The strong influence of the vibration magnitude is also evident from the results attained from ANOVA, presented in Tables 2 and 3 for the $x$ - and $y$-axes, respectively, where $p<0.005$ in most of the frequency range, suggesting nonlinear behavior of 
Table 3. $p$-values attained from single and two- factor ANOVA performed on the seat pan APMS magnitude under lateral vibration

\begin{tabular}{|c|c|c|c|c|c|c|c|c|c|}
\hline \multirow{2}{*}{$\begin{array}{l}\text { Factor } \\
\text { Frequency }(\mathrm{Hz})\end{array}$} & \multicolumn{3}{|c|}{ Excitation $\left(.25, .5,1.0 \mathrm{~m} / \mathrm{s}^{2}\right)$} & \multicolumn{3}{|c|}{ Height $\left(\mathrm{H}_{1}, \mathrm{H}_{2}, \mathrm{H}_{3}\right)$} & \multicolumn{3}{|c|}{ Excitation*Height } \\
\hline & NB & $\mathrm{Wb} 0$ & $\mathrm{WbA}$ & NB & $\mathrm{Wb} 0$ & $\mathrm{WbA}$ & NB & $\mathrm{Wb} 0$ & WbA \\
\hline 0.75 & 0.000 & 0.000 & 0.000 & 0.268 & 0.067 & 0.019 & 0.377 & 0.282 & 0.031 \\
\hline 1.0 & 0.000 & 0.000 & 0.000 & 0.196 & 0.803 & 0.153 & 0.168 & 0.672 & 0.451 \\
\hline 1.5 & 0.005 & 0.000 & 0.000 & 0.131 & 0.743 & 0.028 & 0.246 & 0.097 & 0.463 \\
\hline 2 & 0.001 & 0.000 & 0.000 & 0.001 & 0.811 & 0.153 & 0.755 & 0.535 & 0.428 \\
\hline 2.75 & 0.000 & 0.000 & 0.000 & 0.363 & 0.220 & 0.238 & 0.453 & 0.357 & 0.582 \\
\hline 4 & 0.000 & 0.000 & 0.000 & 0.003 & 0.000 & 0.279 & 0.004 & 0.52 & 0.001 \\
\hline 4.5 & 0.008 & 0.000 & 0.000 & 0.050 & 0.002 & 0.136 & 0.63 & 0.01 & 0.04 \\
\hline 5 & 0.000 & 0.000 & 0.000 & 0.065 & 0.000 & 0.030 & 0.841 & 0.157 & 0.617 \\
\hline 6 & 0.000 & 0.000 & 0.000 & 0.207 & 0.004 & 0.000 & 0.559 & 0.26 & 0.261 \\
\hline 8 & 0.001 & 0.000 & 0.000 & 0.357 & 0.141 & 0.717 & 0.135 & 0.688 & 0.042 \\
\hline
\end{tabular}

Table 4. Effect of posture shown by the $p$-values derived from single-factor ANOVA performed on the seat pan and backrest APMS magnitude data under Fore-and-aft and lateral excitations

\begin{tabular}{ccccccccccccc}
\hline Axis & Frequency $(\mathrm{Hz})$ & 0.75 & 1.0 & 1.5 & 2.0 & 2.75 & 4.0 & 4.5 & 5.0 & 6.0 & 8.0 \\
\hline$x$ - & Wb0VsWbA & 0.428 & 0.037 & 0.000 & 0.000 & 0.038 & 0.854 & 0.011 & 0.000 & 0.000 & 0.002 \\
& 3 Postures & 0.563 & 0.820 & 0.000 & 0.000 & 0.000 & 0.000 & 0.000 & 0.000 & 0.000 & 0.000 \\
$y-$ & Wb0VsWbA & 0.876 & 0.148 & 0.000 & 0.000 & 0.179 & 0.000 & 0.000 & 0.000 & 0.045 & 0.456 \\
& 3 Postures & 0.000 & 0.000 & 0.000 & 0.000 & 0.000 & 0.000 & 0.000 & 0.000 & 0.000 & 0.000 \\
\hline
\end{tabular}
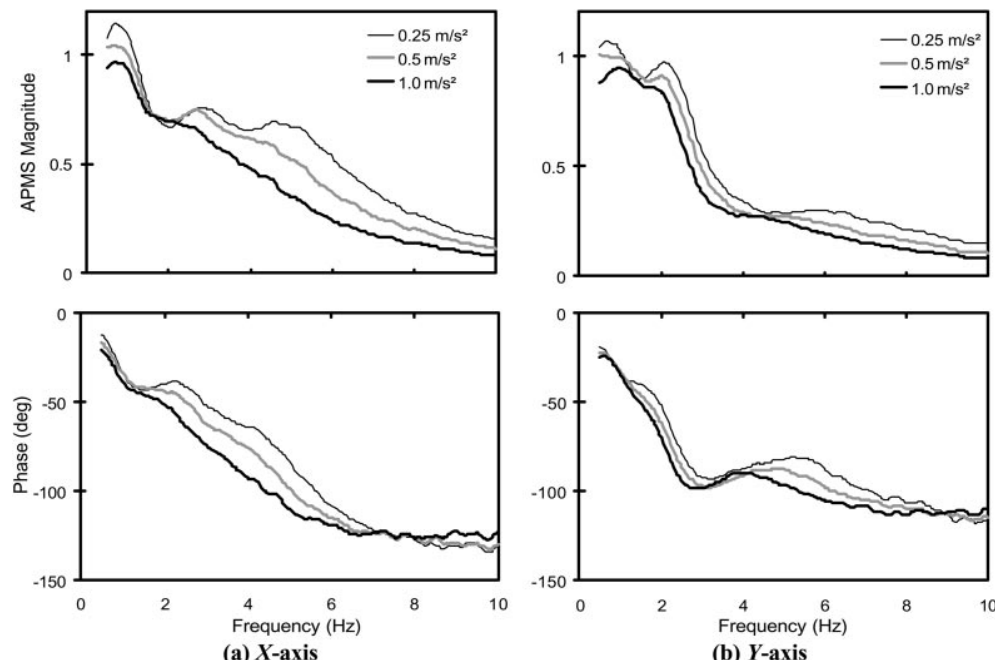

Fig. 3. The Mean normalized seat pan APMS magnitude and phase responses attained under different magnitudes of excitations, seat height $\mathrm{H}_{1}$ and NB posture.

the seated occupant. The effect of vibration magnitude on the seat pan APMS magnitude is highly significant $(p<0.002)$ in the entire frequency range under both axes of vibration and all three sitting postures, with the exception of the low frequency response $(=1.0 \mathrm{~Hz})$ under $\mathrm{WbA}$ posture and $x$ - axis motion.

The variations in the vibration magnitude tend to affect the peak magnitudes and their corresponding frequencies, and the phase response, irrespective of the axis of motion. The magnitude responses for the NB posture (Fig. 3) reveal 

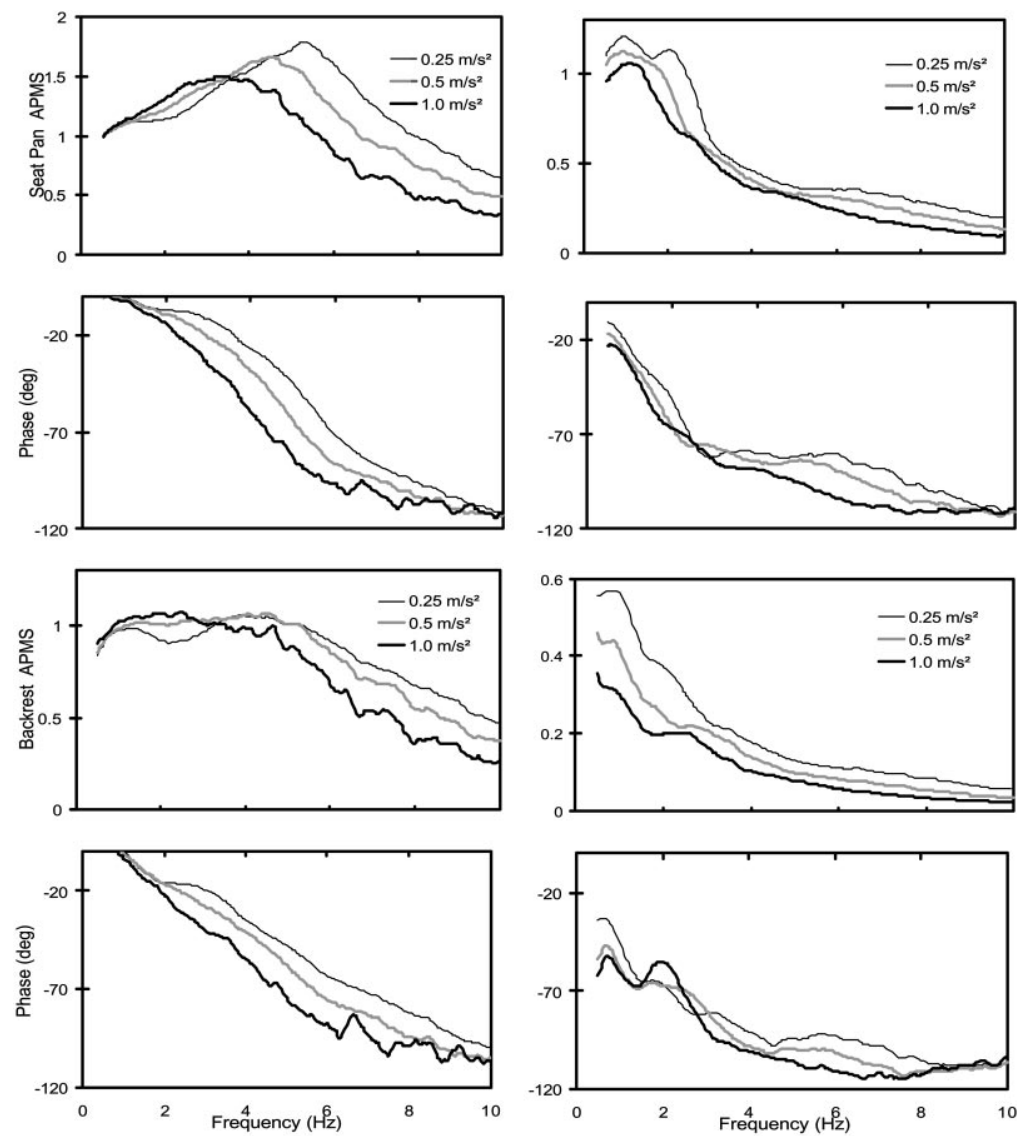

(a) $X$-axis

(b) $Y$-axis

Fig. 4. Influence of excitation magnitude on the mean normalized magnitude and phase responses measured at the seat pan and the backrest (Seat height $-\mathrm{H}_{1}$; Posture - Wb0).

peaks near $0.7,2.8$ and $4.75 \mathrm{~Hz}$ under $x$-axis, and in the $0.7-1.0$ and 1.9-2.1 ranges, and around $6.4 \mathrm{~Hz}$ under the $y$ axis motion. The second and third resonant peaks are more evident under lower magnitude of vibration $\left(0.25 \mathrm{~m} / \mathrm{s}^{2}\right)$, which tend to damp out under higher excitations along both the $x$ and $y$-axes. The primary peak occurs near low frequency of $0.7 \mathrm{~Hz}$, associated with rocking and swaying of the upper body under $x$ - and $y$-axes excitations, irrespective of the excitation magnitude. The primary peak as well as the magnitude response in the entire frequency range tends to decrease with increasing excitation magnitude. The frequencies corresponding to second and third peaks decrease under higher magnitude excitations, suggesting softening effect in these modes. An increase in excitation magnitude generally yields lower phase response for all postures and directions of excitation, particularly above $1 \mathrm{~Hz}$.

Both the magnitude and phase responses show significantly different trends when a vertical back support is used (Fig. 4). Unlike the NB posture, the response characteristics attained under the two directions of motion also differ considerably. Under $x$-axis, the constraint imposed by the vertical backrest generally yields a single-degree-offreedom like behavior of the seat pan APMS magnitude, similar to the vertical biodynamics response, with peak magnitude occurring in the $3.3-5.4 \mathrm{~Hz}$ range. The inclined back support posture also yields similar seat pan magnitude response with peak occurring at relatively lower frequencies $2.7-4.1 \mathrm{~Hz}$. A lower magnitude peak is also observed near $1 \mathrm{~Hz}$ under lower vibration magnitude $\left(0.25 \mathrm{~m} / \mathrm{s}^{2}\right)$ for both postures. The strong effect of the excitation magnitude on the seat pan normalized magnitude is clearly evident from Figs. 4 and 5, which show lower magnitude and the corresponding frequency under higher excitation magnitudes.

The $x$-axis backrest APMS responses show two peaks for the $\mathrm{Wb} 0$ postures in the $1.25-2 \mathrm{~Hz}$ and $4-4.5 \mathrm{~Hz}$ ranges, and three peaks for the WbA posture in the $1-1.2 \mathrm{~Hz}, 2.6-$ $4 \mathrm{~Hz}$ and $7-8 \mathrm{~Hz}$ ranges. The normalized magnitudes of the backrest APMS, however, are considerably smaller than 

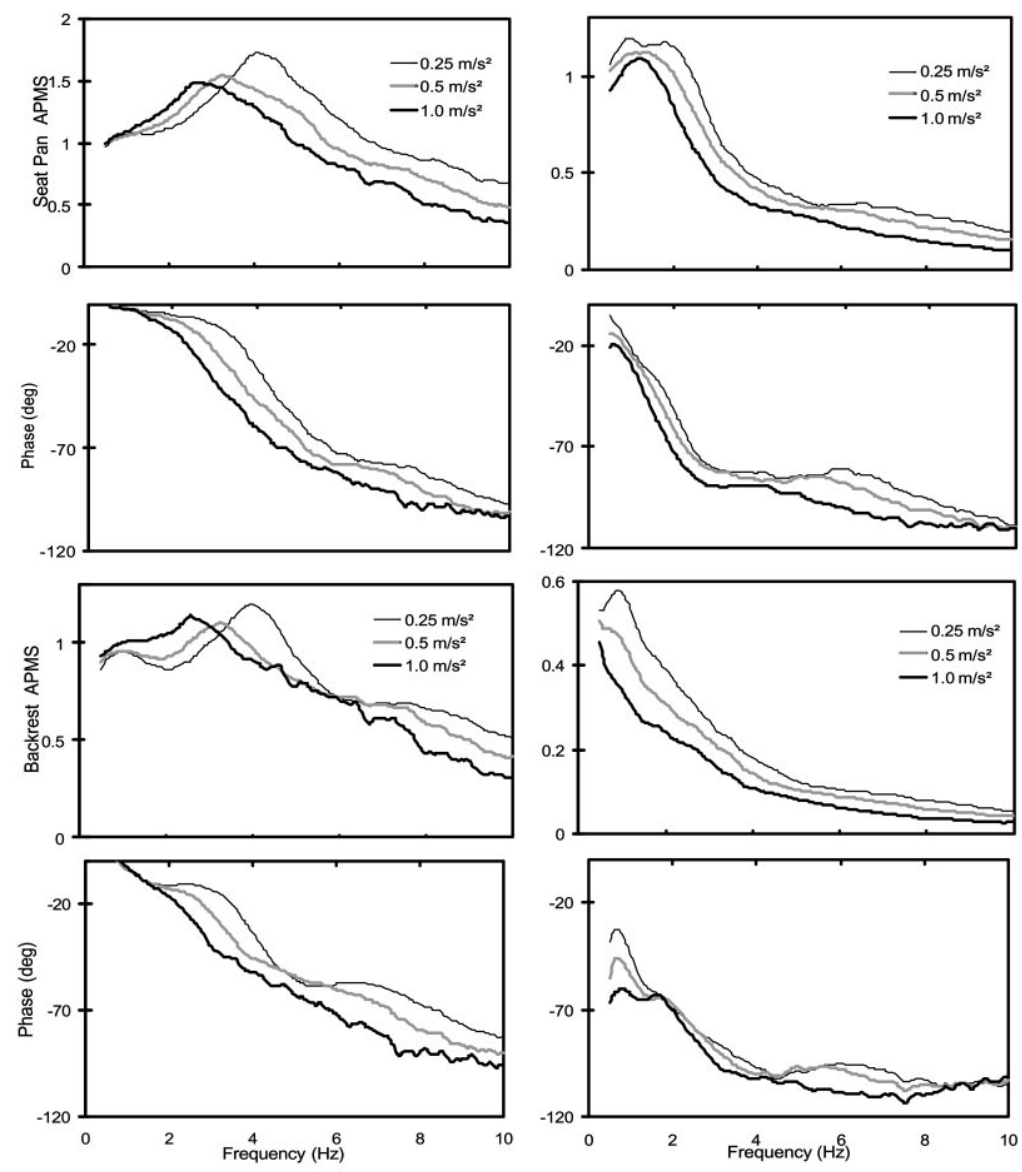

(a) $X$-axis

(b) $Y$-axis

Fig. 5. Influence of excitation magnitude on the mean normalized magnitude and phase responses measured at the seat pan and the backrest (Seat height $-\mathrm{H}_{1}$; Posture - WbA).

those of the seat pan. The two peaks observed for the $\mathrm{Wb} 0$ posture are clearly evident under the lower excitation magnitudes $\left(0.25\right.$ and $\left.0.5 \mathrm{~m} / \mathrm{s}^{2}\right)$, which tend to converge to a single frequency near $2 \mathrm{~Hz}$ under higher excitation $(1 \mathrm{~m} /$ $\mathrm{s}^{2}$ ). Unlike the seat pan APMS, an increase in excitation level yields higher magnitude and the corresponding frequency of the backrest APMS in the lower frequency range for both postures. The second mode frequency and the peak magnitude, however, decrease with increasing excitation level, as observed in the seat pan APMS magnitude. The similar behavior is also observed for the third magnitude peak for the WbA posture.

The mean APMS responses for the back-supported postures under $y$-axis show trends similar to those observed for the NB posture. Under $y$-axis motion, the upper body tends to slide against the backrest resulting in relatively lower interactions with the backrest, while the backrest offers little resistance against the upper body sway. The biodynamic response measured at the seat pan thus resembles that with the NB posture. While the magnitudes of the seat pan APMS are only slightly higher than those for the NB posture, the corresponding frequencies tend to be higher. Lower level excitation yields two magnitude peaks in the $0.9-2.1 \mathrm{~Hz}$ range for both postures. An increase in the excitation level yields a single peak occurring in the $1-1.25 \mathrm{~Hz}$ frequency range. The peak magnitude decreases with increase in the excitation level, while effect on the corresponding frequency is very small. A smaller magnitude peak is also observed in the vicinity of $6.6 \mathrm{~Hz}$ for both postures. The variations in the backrest APMS response with the frequency also show trends comparable to those observed for the seat pan APMS. The primary peak tends to occur around $1 \mathrm{~Hz}$ for both postures under lower level of excitation. Higher excitation causes this frequency to shift towards a lower frequency, suggesting that the peak may occur at a frequency below $0.5 \mathrm{~Hz}$. Higher excitation level also yields lower magnitude response in the 

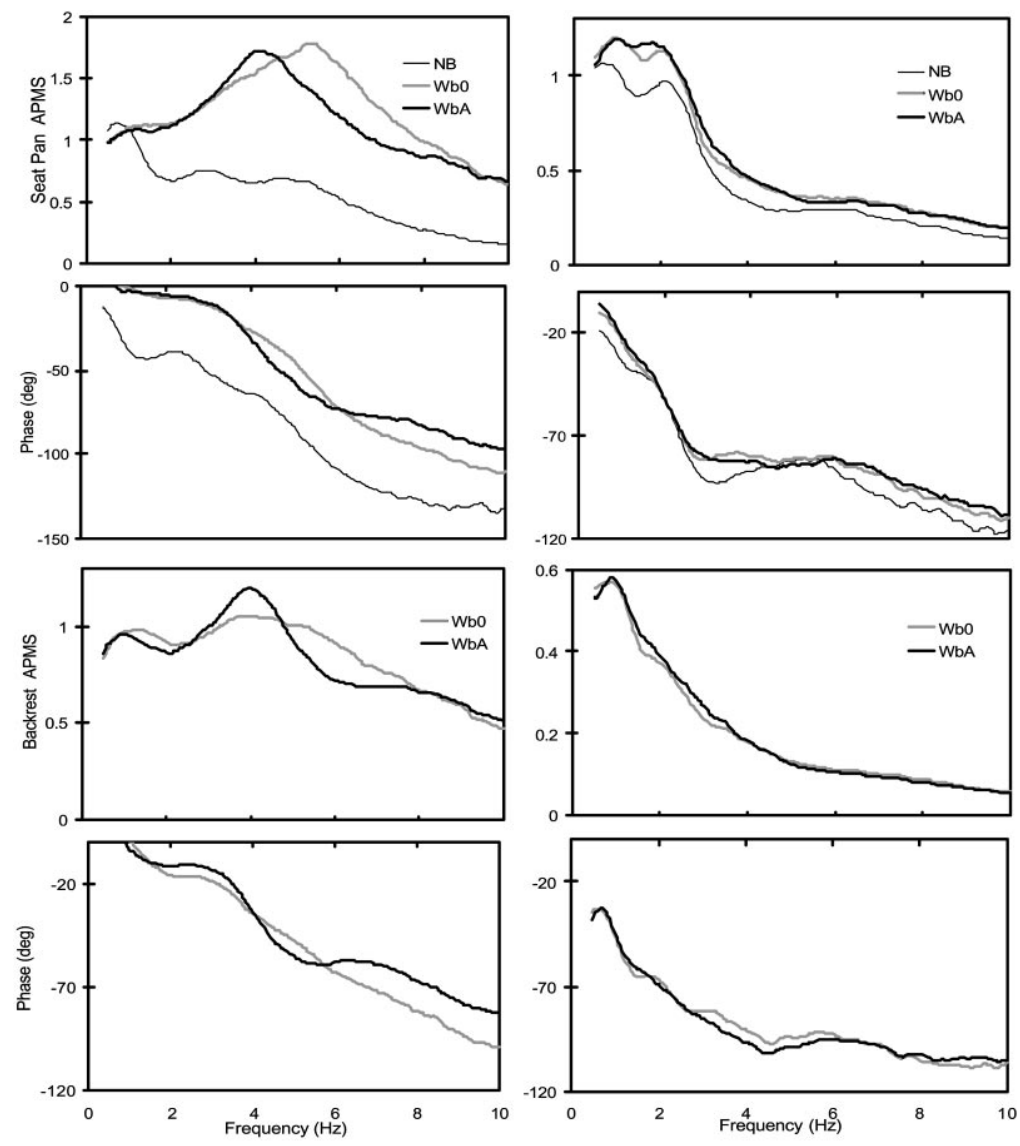

(a) $X$-axis

(b) $Y$-axis

Fig. 6. Influence of posture on the mean normalized magnitude and phase responses measured at the seat pan and the backrest (Seat height: $\mathrm{H}_{1}$; excitation magnitude: $0.25 \mathrm{~m} / \mathrm{s}^{2}$ ).

entire frequency range for both postures. The effects of excitation magnitude on the phase responses are relatively small, when compared to those observed under $x$-axis motion.

\section{Effect of posture}

The results presented in Figs. 3 to 5 clearly show the significant effect of the sitting posture on both the seat pan and the backrest APMS responses, which is further evident from Table 4. The results show significant effects of posture on the seat pan APMS magnitude $(\mathrm{p}<0.001)$, when the variations are considered for all three postures, with the exception of the $x$-axis response at low frequencies $(=1 \mathrm{~Hz})$. The variations in the back support (vertical $v s$ inclined) also show significant effect on the seat pan APMS magnitude in most of the frequency $(\mathrm{p}<0.04)$, except in the vicinity of the resonant peaks around $4 \mathrm{~Hz}$ in the $x$-axis. The back support condition is also significant under the $y$-axis motion in the $1.5-2 \mathrm{~Hz}$ and $4-6 \mathrm{~Hz}$ frequency ranges. The mean normalized seat pan and backrest magnitude and phase responses attained for the three postures, higher seat $\left(\mathrm{H}_{1}=425\right.$ $\mathrm{mm}$ ) and $0.25 \mathrm{~m} / \mathrm{s}^{2} \mathrm{rms}$ acceleration excitation, are further compared in Fig. 6 for both axes.

The results clearly show strong effects of the sitting postures, related to the back support condition, on the peak magnitudes, the corresponding resonant frequencies, and the phase. The NB posture yields considerably lower seat pan magnitudes under both axes of excitation, with three noticeable peaks as discussed above. The frequencies corresponding to the peak magnitudes are comparable with those reported in earlier studies ${ }^{7-9}$. The backrest offers an important resistance to the upper body motions, particularly under longitudinal and vertical excitations. The effect of the back support on the $x$-axis responses, however, is far more significant than those reported for the vertical biodynamics ${ }^{4}$. This may be attributed to relatively large rocking motion of the upper body under longitudinal vibration, participation of comparatively larger portion of the body in the horizontal biodynamics and possible 

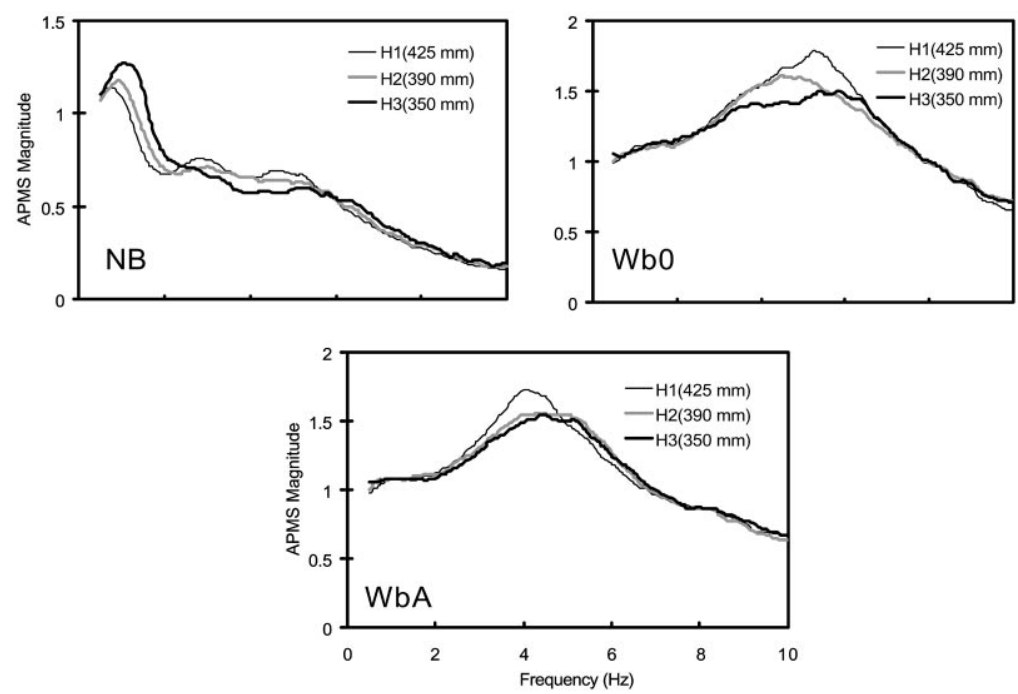

Fig. 7. Influence of seat height on the mean normalized seat pan APMS magnitude and phase under $x$-axis excitation (excitation magnitude $-0.25 \mathrm{~m} / \mathrm{s}^{2}$ ).

contributions due to legs. The effect of the back support on the $y$-axis response is also evident, even though the dynamic interactions of the body with the back support are moderate.

Under the NB postures, the primary peaks in the seat pan APMS magnitudes occur around $0.7 \mathrm{~Hz}$, which are attributed to high magnitude rocking and sway motions of the upper body caused by the $x$ - and $y$-axis excitations, respectively. These motions are stabilized by the muscular actions of the upper torso and by applying increased pressure on the lower legs (calf and feet). The addition of a back support tends to limit the low frequency rocking motion of the upper body under $x$-axis motion, while considerable dynamic interactions with the backrest would occur. The backrest support causes the stiffening of the body under $x$-axis motion, as evident from considerably higher frequency corresponding to the primary peak response (near 5.4 and $4.1 \mathrm{~Hz}$ for the Wb0 and $\mathrm{WbA}$ postures, respectively. The biodynamic behaviour of the seated occupant seated with a back support and exposed to $x$-axis vibration tends to dominate around this mode, and thereby resembles that of a single-degree-of-freedom system. The backrest, however, serves as another source of vibration to the seated occupant, which tends to cause considerably higher APMS magnitude responses, as observed in Fig. 6 for both $\mathrm{Wb} 0$ and $\mathrm{WbA}$ postures. A relaxed posture with an inclined backrest causes a softening effect when compared to an erect posture with a vertical backrest. An inclined backsupported posture thus yields peak seat pan APMS response at a lower frequency (near $4.1 \mathrm{~Hz}$ ). The peak seat pan APMS magnitude also decreases slightly with the WbA posture; both the lower magnitude and lower frequency may be beneficial in reducing the strain on the lumbar spine. An inclined backrest, however, supports a larger portion of the upper body mass and thus causes higher backrest magnitude response near $4.1 \mathrm{~Hz}$.

Under lateral vibration, the back support offers limited resistance against the body sway to help stabilize the sitting posture. The back-supported postures thus yield relatively higher frequency of the primary peak in the seat pan APMS response, when compared to that of the NB posture. The additional vibration energy transmitted to the upper back also yields relatively higher peak magnitude, as evident in Fig. 6. The backrest APMS responses, however, are not influenced by the back support due to relatively lower interactions of the upper body with the backrest along the lateral axis. Moreover, the variations in the back support conditions considered in this study have only minimal effect the seat pan as well as the backrest APMS phase responses under lateral excitations. The phase responses under longitudinal excitations, however, are strongly influenced by the back support. The NB posture yields considerably lower phase response between the seat pan force and the longitudinal acceleration, when compared to those attained with the back-supported postures. At excitation frequencies above $6 \mathrm{~Hz}$, an inclined back support yields higher phase response than the vertical back support.

\section{Effect of seat height}

Figure 7 illustrates comparisons of the mean seat pan magnitude responses of the seated occupant obtained for the three seat heights considered in the study. The figure 
shows the responses attained with three sitting postures, while exposed to $0.25 \mathrm{~m} / \mathrm{s}^{2}$ excitation along the $x$-axis. The effect of seat height was observed to very small on the seat pan APMS phase and the backrest APMS magnitude and phase under $x$-axis, and all the responses under $y$-axis. The figure thus illustrates the effects on the $x$-axis seat pan normalized magnitude responses alone. The effect of the seat height is predominant on the magnitude response in the vicinity of the resonant frequencies, which is further evident from the ANOVA results ( $\mathrm{p}<0.04$; Table 2), irrespective of the posture. The results also show strong interactions between the seat height and the excitation magnitude around the same frequencies. The seat height effect was more evident for the NB posture. A higher seat with this posture generally encouraged the subjects to shift more weight towards the feet in an attempt to stabilize their posture. A lower seat height provided a more stable posture, and the resulting stiffening effect caused the fundamental frequency and the magnitude to increase slightly. The peak magnitude response with back supported postures, however, decrease with the decrease in the seat height. It is speculated that the subjects seated on a lower seat tend to make full use of the back support and thereby reduce the forces on the seat pan, which could cause lower peak APMS magnitude in the vicinity of the resonant frequencies. While the effect of seat height is more evident under lower vibration magnitude, the effect was observed to be smaller under higher magnitudes of excitations.

\section{Discussions in view of the reported results}

The biodynamic responses measured at the seat pan of seated occupants without a back support exposed to sinusoidal and random horizontal vibration along the $x$ - and $y$-axes have been reported in a few studies ${ }^{7-9)}$. Fairley and Griffin ${ }^{7)}$ and Nawayseh and Griffin ${ }^{6}$ have also reported the seat pan APMS of occupants seated with a vertical backrest support. The mean seat pan APMS responses obtained in the present study are compared with those reported, in Figs. 8-11. The comparisons reveal reasonably good agreements of the mean data with the reported results for the back-unsupported posture, in terms of the magnitudes as well as the corresponding frequencies, under $x$ - and $y$-axis motions. The peak magnitudes obtained with NB posture under $x$ - and $y$ axes, in the vicinity of $0.7 \mathrm{~Hz}$, agree well with those reported by Fairley and Griffin ${ }^{7}$, as shown in Figs. 8(a) and 8(b). The observed variations in the peak magnitudes can be attributed to the differences in the test conditions and the anthropometric features of the test subjects. The other studies $^{8,9)}$ have reported the similar responses at frequencies

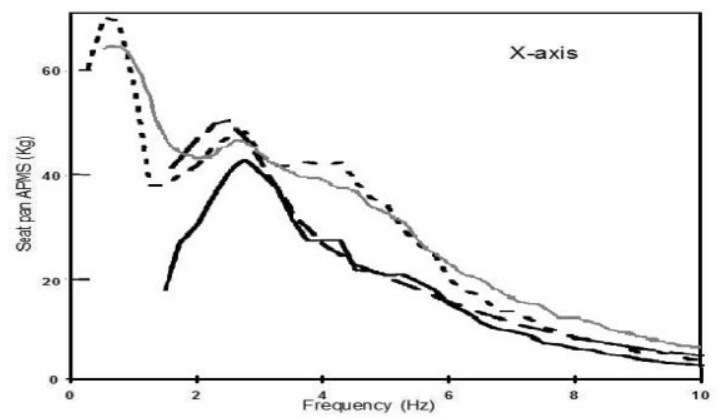

(a)

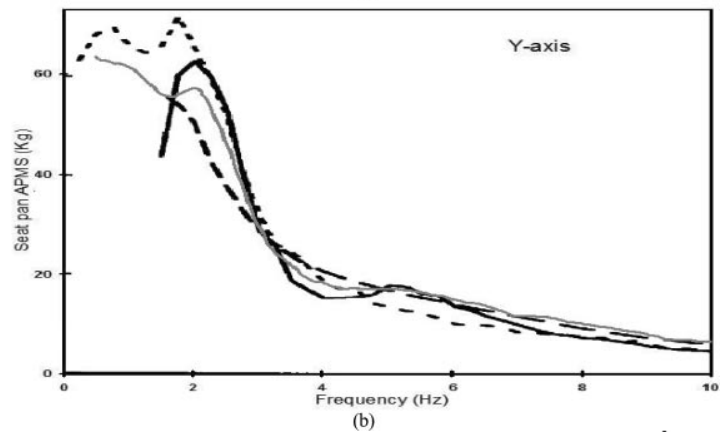

Fig. 8. Comparison of mean seat pan APMS measured in this study under $0.5 \mathrm{~m} / \mathrm{s}^{2} \mathrm{rms}$ acceleration — to those with reported data.

(- - - - Fairley and Griffin ${ }^{7)}$ under $0.5 \mathrm{~m} / \mathrm{s}^{2} \mathrm{rms}$ random excitation; - Mansfield and Lundström ${ }^{9)}$ under $0.5 \mathrm{~m} / \mathrm{s}^{2} \mathrm{rms}$ random excitation and - - Holmlund and Lundström ${ }^{8)}$ using sinusoidal excitation at $0.5 \mathrm{~m} / \mathrm{s}^{2} \mathrm{rms}$ ).

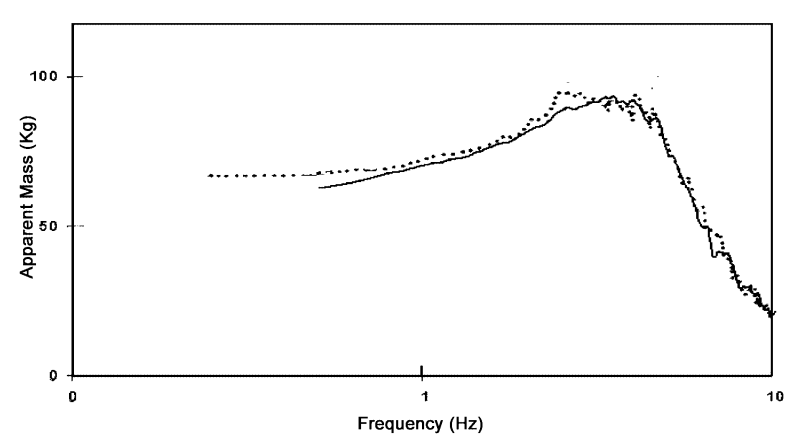

Fig. 9. Comparison of mean seat pan APMS magnitude measured with the $\mathrm{Wb0}$ posture under $1.0 \mathrm{~m} / \mathrm{s}^{2} \mathrm{rms}$ fore-and-aft excitation with the reported data.

(- - - - Fairley and Griffin ${ }^{7)} \longrightarrow$ present study).

well above the primary resonant frequency, and thus could not be compared. Good agreements in the magnitude responses around the second and third modes, however, can be observed.

The seat pan APMS magnitude response, reported for the Wb0 posture under $x$-axis in ${ }^{7}$, also agrees well with that of 


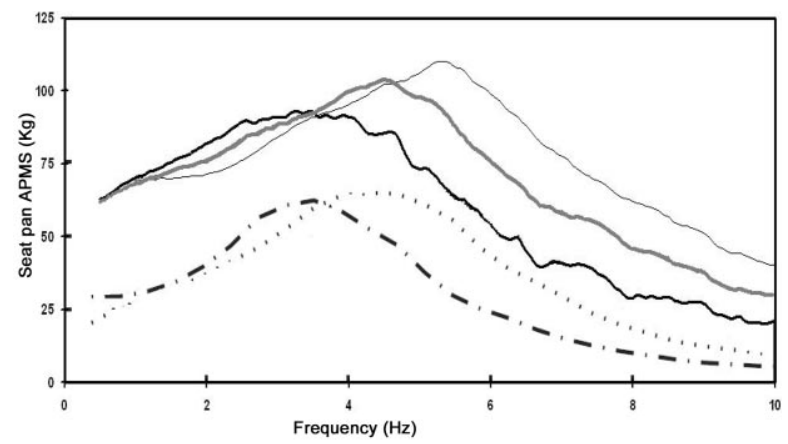

Fig. 10. Comparison of mean seat pan APMS magnitude measured with $\mathrm{Wb0}$ posture measured under different magnitude fore-andaft excitations.

(Present study: $-0.25 \mathrm{~m} / \mathrm{s}^{2} ; 0.5 \mathrm{~m} / \mathrm{s}^{2} ;-1.0 \mathrm{~m} / \mathrm{s}^{2} \mathrm{rms}$; - Nawayseh and Griffin ${ }^{6}$ : - - - $0.25 \mathrm{~m} / \mathrm{s}^{2} ;---0.625$ $\left.\mathrm{m} / \mathrm{s}^{2} \mathrm{rms}\right)$.

the present study, as evident in Fig. 9. The median seat pan magnitude responses measured under different magnitudes of $x$-axis excitations $\left(0.125,0.25,0.625\right.$ and $1.25 \mathrm{~m} / \mathrm{s}^{2} \mathrm{rms}$ acceleration) reported in a recent study ${ }^{6}$ are also compared with the mean responses attained under three excitations levels in Fig. 10. While the comparisons show similar trends in the seat pan magnitude responses, the magnitudes of the reported data tend to be considerably lower than those of the present study in the entire frequency range. The reported data also shows low frequency magnitude of approximately $25 \mathrm{~kg}$, while the mean body weight of the test subject population $(76.1 \mathrm{~kg})$ is comparable with that of the present study $(72.2 \mathrm{~kg})$. The magnitudes of the reported data are also significantly lower than that reported by Fairley and Griffin $^{7}$. The frequencies corresponding to the peak magnitudes of the reported data sets are also considerably lower than those observed from the data acquired in this study. The backrest APMS magnitude response measured in the study, however, agrees reasonably well with the data acquired in this study as illustrated in Fig. 11.

\section{Conclusions}

The dynamic response characteristics of seated human subjects exposed to fore-aft ( $x$-axis) and lateral ( $y$-axis) vibration show considerable dynamic interactions between the upper body and the seat backrest, apart from those of the body-seat pan. The apparent mass responses measured at the seat pan and the backrest thus clearly show strong influences of the back support condition. The seat pan APMS magnitude responses of occupants seated without a back support dominate around the low frequency of $0.7 \mathrm{~Hz}$,

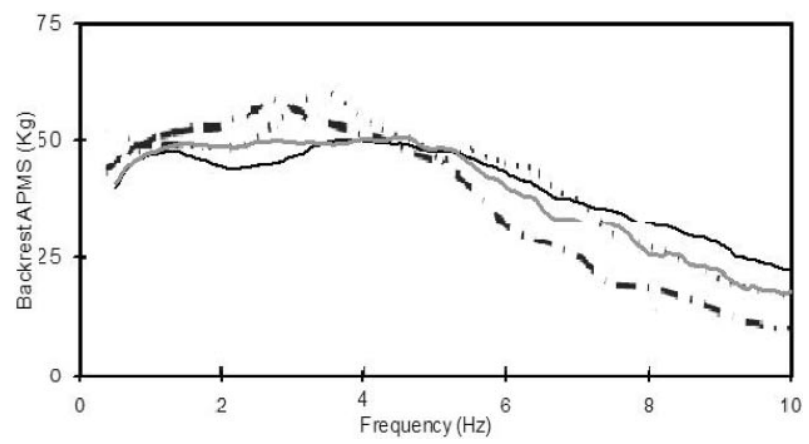

Fig. 11. Comparison of mean backrest APMS magnitude measured with $\mathrm{Wb0}$ posture measured under different magnitude fore-andaft excitations.

(Present study: $-0.25 \mathrm{~m} / \mathrm{s}^{2} ;-0.5 \mathrm{~m} / \mathrm{s}^{2} \mathrm{rms}$; Nawayseh and Griffin ${ }^{6)}$ : - - $-0.25 \mathrm{~m} / \mathrm{s}^{2} ;---0.625 \mathrm{~m} / \mathrm{s}^{2} \mathrm{rms}$ ).

associated with the rocking and swaying motions of the upper body under fore-aft and lateral vibration, respectively. The presence of a backrest helps to stabilize the sitting posture by limiting the motions of the upper body, particularly under fore-aft excitations, and thereby stiffening of the body. The peak seat pan APMS magnitude occurs in the $3.3-5.4 \mathrm{~Hz}$ range, when a vertical back support is used, depending upon the excitation magnitude. The relaxed posture with an inclined back support causes some softening of the body, resulting in peak magnitude response in the $2.7-4.1 \mathrm{~Hz}$ range. The use of a back support however yields considerable interactions of the upper body with the backrest, while the backrest serves as another source of vibration. The peak magnitude of the seat pan APMS thus tends to be considerably higher with the back-supported postures. The seat pan APMS responses of the seated body without a back support also reveal two secondary peaks in the magnitude occurring at relatively higher frequencies. The addition of back support causes the seat pan response to converge mostly to a single primary peak, resulting in a single-degree-of-freedom like behavior, with peak occurring in the 2.7-5.4 and 0.9-2.1 $\mathrm{Hz}$ ranges under $x$ - and $y$-axis motions, respectively. The variations in the normalized APMS magnitudes under the NB sitting posture could be considered to follow the $w_{d^{-}}$ weighting recommended in ISO-2631-1 ${ }^{19}$, for both axes of excitations. The magnitude responses attained with the backsupported postures, however, deviate significantly from the weighting function.

Unlike the widely reported responses of seated occupants under vertical vibration, the responses to horizontal vibration show strong effect of excitation magnitude. Higher excitation magnitudes yield considerably lower peak magnitudes of 
the seat pan APMS and the corresponding frequencies, irrespective of the posture and the direction of motion. The results suggest that the biodynamic responses of seated occupants exposed to horizontal vibration are strongly nonlinear. The study further shows considerable magnitudes of the apparent mass response measured at the seat back under fore-aft motions, suggesting strong interactions with the backrest. Such interactions along the side-to-side motions, however, are relatively small. The results suggest that the biodynamic characterization of seated occupants exposed to horizontal vibration requires appropriate considerations of the interactions with the backrest.

\section{Acknowledgements}

This work was carried out with the financial support from NATEQ (Quebec). The technical assistance provided by Mr. Jose Esteves is deeply acknowledged.

\section{References}

1) Fairley TE, Griffin MJ (1989) The apparent mass of the seated human body: vertical vibration. J Biomech 22, 81-94.

2) Holmlund P, Lundström R, Lindnerg L (2000) Mechanical Impedance of the human body in the Vertical direction. Appl Ergon 31, 415-22.

3) Boileau P-É, Wu X, Rakheja S (1998) Definition of a range of idealized values to characterize seated body biodynamic response under vertical vibration. J Sound Vib 215, 841-62.

4) Wang W, Rakheja S, Boileau P-É (2004) Effects of sitting postures on biodynamic response of seated occupants under vertical vibration. Int J Ergon 34, 289306.

5) Mansfield NJ, Griffin MJ (2000) Non-linearites in apparent mass and transmissibility during exposure to whole-body vertical vibration. J Biomech 33, 933-41.

6) Nawayseh N, Griffin MJ (2005) Tri-axial forces at the seat and backrest during whole body fore-and-aft vibration. J Sound Vib 281, 921-42.

7) Fairley TE, Griffin MJ (1990) The apparent mass of the seated human body in the fore-and-aft and lateral directions. J Sound Vib 139, 299-306.

8) Holmlund P, Lundström R (1998) Mechanical Impedance of the human body in the horizontal direction. J Sound Vib 215, 801-12.

9) Mansfield NJ, Lundström R (1999) The apparent mass of the human body exposed to non-orthogonal horizontal vibration. J Biomech 32, 1269-78.

10) Kumar A, Mahajan P, Mohan D, Varghese M (2001) Tractor vibration severity and driver health: a study from rural India. J Agric Eng Res 80, 313-28.

11) Marsili A, Ragni L, Santoro G, Servadio P, Vassalini G (2002) Innovative systems to reduce vibrations on agricultural tractors: comparative analysis of acceleration transmitted through the driving seat. Biosystems Eng 81, 35-47.

12) Bovenzi M, Pinto I, Stacchini N (2002) Low back pain in port machinery operators. J Sound Vib 253, 3-20.

13) Fukuda T, Takeuchi D, Shimizu H (2001) Study on the evaluation of vibration exposure during vehicle operation and health: Is it practical and viable way of predicting the effects on people? In: Proceedings of Japan Group Meeting on Human Response to Vibration 2001.

14) Programme for technical risk factors national institute for working life research network on dectection and prevention of injuries due to occupational vibration exposures (EU BIOMED 2 concerted Action Programme) 2003. In: Centralized European database for whole-body vibration in the earth-moving vehicles. <http://umetech.niwl.se/vibration/WBVHome.html.>

15) Golding JF, Markley HM, Stott JRR (1994) The effects of motion, body axis, and posture on motion sickness induced by low frequency linear oscillation. In: Proceedings of United Kingdom Group Meeting on Human Response to Vibration 1994. 13.

16) Golding JF, Finch MI, Stott JRR (1995) Frequency effect of $0.35-1.0 \mathrm{~Hz}$ horizontal translational oscillation on motion sickness and the somatogravic illusion. In: Proceedings of United Kingdom Group Meeting on Human Response to Vibration 1995. 13.

17) Golding JF, Markley HM (1994) The effect of frequency on motion sickness and the somatogravic illusion, induced by low frequency linear oscillation in the horizontal direction. In: Proceedings of United Kingdom Group Meeting on Human Response to Vibration 1994. 14.

18) Winter DA (1979) Biomechanics of human movement 151 (Now published as Biomechanics and motor control of human movement). John Wiley \& Sons, Toronto, Canada.

19) International Organization for Standardization (1997) Mechanical vibration and shock-evaluation of human exposure to whole-body vibration. Part I: General requirements. International Standard ISO 2631-1. 